\title{
"Mamãe é down": a sexualidade da pessoa com deficiência na trama discursiva da Revista Época
}

\author{
Ana Flávia Teodoro de Mendonça Oliveira* \\ Clarissa Martins de Araújo**
}

\section{Resumo}

Este artigo analisa um artefato cultural midiático que produz narrativas sobre a pessoa com deficiência e sua sexualidade, como observado na reportagem Mamãe é Down, produzida pela revista Época. Com base na perspectiva pós-estruturalista dos Estudos Culturais e nos estudos foucaultianos, o objetivo é analisar a representação cultural da deficiência e identificar os estereótipos e as essencializaçôes existentes no discurso sobre esses sujeitos. Os resultados indicam que as narrativas sobre a deficiência se articulam com um aparato conceitual, advindo de um saber médico, constituindo uma ideia de deficiência intimamente relacionada à questáo biológica. Assim, apresentamse as causas, o diagnóstico e os possíveis tratamentos oferecidos a esses sujeitos. Nesse jogo de forças, se por um lado os discursos produzem a ideia de uma sexualidade atrelada aos aspectos biológicos, por outro, produzem também a representação cultural de que as pessoas com deficiência podem usufruir de sua sexualidade, de uma vida a dois e da experiência da maternidade.

Palavras-chave: Deficiência; Representação cultural; Estereótipo.

\footnotetext{
* Doutora em Educação e professora adjunta II da faculdade de Educação da Universidade Federal de Goiás, Goiânia, Goiás, Brasil.

** Professora doutora em Ciências da Educação pela Universidade de Toulouse-Jean Jaurès, Toulouse, França.
} 


\section{"Mom is down": the sexuality of people with disabilities within discourse of Época magazine}

\section{Abstract}

This article analyzes a media cultural artifact that produces narratives about people with disabilities and their sexuality, as noticed in the report Mom is Down, published by Época magazine. Based on post-structuralist perspective of Cultural Studies and on Foucault's approach, the goal of this paper is to analyze the cultural representation of disability and also to identify stereotypes and existing essentializations in the discourse about people with Down. The results indicate that the narratives about disability are linked with a conceptual apparatus, coming from a medical knowledge, providing a sense of disability closely related to the biological question. Thus, the causes, the diagnosis and the possible treatments offered to these subjects are presented. In this game of forces, there are narratives in which the sexuality concept is not only connected with biological aspects, but also with the cultural representation that people with disabilities can enjoy their sexuality, a life together and the experience of motherhood.

Keywords: Disability; Cultural representation; Stereotype.

\section{Introdução}

A reportagem publicada no site da revista Época, em 05 de setembro de 2008, intitulada "Mamãe é Down", apresenta o cotidiano de um casal com deficiência intelectual, tendo como pano de fundo a questão da maternidade ou da capacidade reprodutiva das mulheres com Síndrome de Down e a probabilidade de gerarem filhos "normais". Trata-se de uma narrativa de alteridade por excelência, que tem em seu cerne a exploração de uma temática importante, que produz significados sobre a deficiência e sobre sexualidade.

Diante disso, a opção por analisar os discursos emergentes da revista Época, deve-se ao fato de entendermos que esse artefato cultural midiático exerce uma pedagogia cultural que ensina às pessoas o que é ser "deficiente". Essa reflexão parte do conceito de pedagogia cultural assinalado por Steinberg (1997), que revela que educação pode ocorrer numa variedade de locais sociais nos quais se incluem as instituiçóes de ensino formais, como a escola ou a universidade, porém não se limita a elas. $\mathrm{Na}$ perspectiva assumida pela autora, "lugares pedagógicos são aqueles onde o poder se organiza e se exercita, tais como bibliotecas, TV, filmes, jornais, revistas, brinquedos, anúncios, videogames, livros, esportes, etc." (STEINBERG, 1997, p.102).

O conceito de pedagogia cultural amplia a concepção de educação e leva-nos a compreender que os artefatos culturais midiáticos podem transmitir uma variedade de conhecimentos, mas, sobretudo, podem produzir subjetividades, marcando as diferenças, dizendo quem pode estar incluído ou excluído. Sobre essas pedagogias, Albuquerque Jr. (2011, p.22) afirma que: 
[...] Vivemos em sociedades e culturas em que uma multiplicidade de pedagogias opera no cotidiano visando elaborar subjetividades, produzir identidades, adestrar e dirigir corpos e gestos, interditar, permitir e incitar ou ensinar hábitos, costumes e habilidades, traçar interditos, marcar diferenças entre o admitido e o excluído, valorar diferencialmente e hierarquicamente gostos, preferências, opções, pertencimentos, etc.

Dessa maneira, ao esquadrinhar os discursos da revista Época, pretendemos investigar as representaçóes potencializadas e as excluídas na emergência de uma trama discursiva em que se coloca a sexualidade e a capacidade reprodutiva da pessoa com deficiência como foco central de discussão. No entanto, faz-se necessário destacar que concebemos "representação" de acordo com a abordagem construcionista de Hall (1997). A representação é, para o autor, entendida como:

[...] O processo pelo qual os membros de uma cultura utilizam a língua (amplamente definida como qualquer sistema que empregue signos, qualquer sistema significante) para produzir significados. Esta definição já carrega a importante premissa de que as coisas - objetos, pessoas, eventos do mundo - não têm em si qualquer significado estabelecido, final ou verdadeiro. Somos nós - na sociedade, nas culturas humanas - que fazemos as coisas significarem, que significamos. (HALL, 1997, p.61).

Analisar os discursos, nesse registro, implica atentar também para as estratégias de estereotipização utilizadas na produção da deficiência e da sexualidade da pessoa com deficiência. Em relação aos estereótipos, Larossa (1994, p.83) afirma que "são os lugares comuns do discurso, o que todo mundo diz, o que todo mundo sabe". Sendo assim, considera-se como estereótipo algo que é imediatamente compreendido, que é tomado como uma verdade, de modo automático e sem reflexão. O autor salienta que:

[...] É grande o poder dos estereótipos, tâo evidentes e tão convincentes ao mesmo tempo. Os procedimentos que fabricam os estereótipos de nosso discurso, os preconceitos de nossa moral e os hábitos de nossa maneira de conduzir-nos nos mostram que somos menos livres do que pensamos, quando falamos, julgamos ou fazemos coisas. (LARROSA, 1994, p.75).

Em face dessas suposiçôes, pensamos na importância de não nos restringirmos a uma análise que priorize apenas a identificação das representaçóes culturais da deficiência. Mais do que isso, consideramos relevante destacar os jogos de correlaçáo de forças e as relaçôes de poder-saber que estabelecem critérios de validade e legitimidade acerca da deficiência, partindo do entendimento de que "todas as práticas de significação que produzem significados envolvem relaçôes de poder, incluindo o poder para definir quem é incluído e quem é excluído" (WOODWARD, 2009, p.18).

Assim, ao reconhecer a deficiência como objeto cultural e ao definir as relaçóes entre deficiência e poder como elementos centrais de nosso estudo, valemo-nos do pensamento de Michel Foucault. Essa perspectiva teórica nos ajuda a entender que o poder "incita, induz, desvia, facilita ou torna mais difícil, amplia ou limita, torna 
mais ou menos provável; no limite, ele coage ou impede absolutamente, mas é sempre uma maneira de agir sobre um ou vários sujeitos ativos" (FOUCAULT, 1995, p. 243).

A partir desse raciocínio, interessa-nos examinar os discursos para saber até que ponto estáo imbuídos de narrativas que constroem o outro com deficiência, enquanto objeto de conhecimento, num processo de objetivação científica. Sobre esse processo de objetivação, Larrosa (1994, p.50) nos diz que:

[...] É no momento em que se objetivam certos aspectos do humano que se torna possível a manipulação técnica institucionalizada dos indivíduos. E, inversamente, é no momento em que se desdobra sobre o social um conjunto de práticas institucionalizadas de manipulação dos indivíduos que se torna possível sua objetivação "científica”.

Nessa perspectiva, a análise dos discursos que produzem a deficiência na trama discursiva da revista Época fundamenta-se na análise arqueológica de Foucault (2013). Sobre essa abordagem, o autor explica que:

[...] A arqueologia busca definir não os pensamentos, as representações, as imagens, os temas obsessões que se ocultam ou se manifestam nos discursos, mas os próprios discursos, enquanto práticas que obedecem a regras. [...] Não é o retorno ao próprio segredo da origem; é a descrição sistemática de um discurso-objeto. (FOUCAULT, 2013, p.169-170).

Dessa forma, ao analisar os discursos sobre a pessoa com deficiência na revista Época, pensamos ser possível desnaturalizar a deficiência, rompendo com a ideia de transparência da linguagem. E, mais do que isso, ao desvelar a representação cultural da deficiência, pretendemos contribuir para a ruptura de certezas, verdades e crenças preestabelecidas a respeito dos sujeitos com deficiência e de sua sexualidade.

\section{Os discursos sobre a deficiência na Revista Época: descrição da função enunciativa}

Para discutir a produção do sujeito com deficiência na reportagem da revista Época e sua imersão no jogo do poder-saber, apresentamos, inicialmente, uma análise do lugar de enunciação da deficiência. Nesse sentido, cabe esclarecer que os lugares de enunciaçáo podem ser considerado também como o lugar em que se legitima, interdita e, de acordo com suas próprias regras, faz os discursos reaparecerem.

Assim, o lugar de onde os sujeitos enunciam a deficiência é a revista Época, lançada em 25 de maio de 1998, publicada pela Editora Globo. Atualmente, a linha editorial da revista Época dá ênfase a reportagens de saúde, cultura, bem-estar e comportamento. Além desses assuntos, os temas políticos costumam ser abordados com destaque no referido veículo.

Dessa forma, é preciso frisar que a revista Época recebe o seu estatuto de enunciador privilegiado por pertencer a uma das principais organizaçóes de imprensa e entretenimento do país - o Grupo Globo. Isso significa que as formas de narrar 
e representar a deficiência são potencializadas pela própria autoridade conferida a esse espaço midiático, haja vista que o Grupo Globo atua em diversos segmentos, possuindo poderosas ferramentas de enunciação, que confere grande visibilidade às questôes relacionadas à alteridade.

Outra questão importante a ressaltar é a heterogeneidade dos sujeitos encarregados de produzir a deficiência, demonstrando que os discursos que circulam nesse artefato cultural estão abertos a diferentes autorias e a filiaçóes diversas. Tal constataçâo direciona-nos a evidenciar o status dos sujeitos autorizados a narrar a deficiência na revista, colocando em evidência os sujeitos em sua função de autor. Cabe esclarecer que, para Foucault (2013), o autor não é entendido como um indivíduo falante que pronunciou ou escreveu um texto, nem funciona como um nome próprio, mas o autor como princípio de agrupamento do discurso, como unidade e origem de suas significaçôes, como foco de coerência.

Assim, na revista Época, a sexualidade da pessoa com deficiência foi narrada por diferentes sujeitos. Em relação às fontes especializadas, foram consultadas uma antropóloga e professora de Bioética da Universidade de Brasília (UnB), um geneticista do Rhode Islande Hospital e outro geneticista do Instituto Fernandes Figueira, além de um pediatra responsável pelo departamento de genética clínica do Hospital Infantil Darcy Vargas.

O discurso do médico, valendo-se de dados estatísticos, produz significados sobre a deficiência, assumindo um valor de verdade, tendo em vista que a hegemonia ou o poder do médico de narrar a deficiência deve-se ao status conferido a esse sujeito no decorrer da própria história da deficiência. Sobre o status desse profissional, Foucault (1996, p.57) salienta que:

[...] Esse status dos médicos é, em geral, bastante singular em todas as formas de sociedade e de civilização: ele não é, quase nunca, um personagem indiferenciado ou intercambiável. A fala médica năo pode vir de quem quer que seja; seu valor, sua eficácia, seus próprios poderes terapêuticos e, de maneira geral, sua existência como fala médica não são dissociáveis do personagem, definido por status, que tem o direito de articulá-lo, reivindicando para si o poder de conjurar o sofrimento e a morte.

Outrossim, além dos profissionais de diversas áreas, verificamos também a participação dos familiares narrando a deficiência, levando-nos a constatar que a instituição familiar, entre tantas outras, destaca-se como aquela que detém o poder de dizibilidade sobre os diversos aspectos da vida dessas pessoas.

Em contrapartida, é importante constatar o silenciamento das vozes das pessoas com deficiência. Diante dos diversos sujeitos que discursam a respeito da deficiência, revela-se o fato de as pessoas com deficiência encontrarem-se quase sempre na posição de tema narrado pelo outro, fazendo com que, na maioria dos registros, as suas vozes sejam interditadas. Dessa forma, Gabriela e Fábio, o casal com deficiência intelectual, não são consultados em assuntos referentes à experiência da maternidade, da paternidade ou em relaçáo à sua própria sexualidade. 
No entanto, esse silenciamento ou a reduzida possibilidade de falar sobre suas vidas estáo diretamente implicadas com as próprias relaçôes de poder, que historicamente foram legitimando o poder de médicos, pais, professores, psicólogos para dar voz às pessoas com deficiência. Essa observação leva-nos a atentar para o que Tomazini (1998, p.125) fala sobre as interdiçóes ao discurso da pessoa com deficiência.

[...] Áqueles indivíduos marcados por uma distinção, efetivamente não é dada a palavra. Não lhes perguntamos o que querem ou náo, o que precisam e o que realmente lhes interessa. Seu saber é desqualificado, considerado náo competente ou insuficientemente elaborado: saber ingênuo, hierarquicamente inferior, abaixo do nível requerido de conhecimento e de cientificidade.

Tais considerações mostram-nos que não há uma função unificante na produção da deficiência na revista Época, mas há uma luta pelo poder de dizer sobre esses sujeitos. Essa luta revela-se por meio dos vários campos de saber (medicina, antropologia, dentre outros) envolvidos nesse processo, mediante a diversidade de sujeitos, com status diferenciados, vindos de lugares diversos, disputando a hegemonia de uma discursividade sobre a deficiência.

\section{A sexualidade da pessoa com deficiência - revelando prazeres e poderes}

$\mathrm{Na}$ construção do discurso acerca da maternidade e da sexualidade dos sujeitos com deficiência intelectual, os fatores biológicos ganham proeminência, fazendo aparecer enunciados marcados por explicaçóes acerca da capacidade reprodutiva das pessoas com deficiência, como podemos ver nos excertos abaixo:

É raro, mas mulheres Downs podem engravidar. "No mundo todo, há apenas cerca de 30 casos documentados de mulheres Downs que tiveram filhos", diz Siegfried M. Pueschel, geneticista do Rhode Island Hospital, nos Estados Unidos, um dos maiores estudiosos da síndrome. (Revista Época online, 2008).

Com a estratégia de apresentar, de discutir e de discursar a respeito da deficiência, surgem representaçóes que acabam subvertendo e desestabilizando as certezas em relaçâo à sexualidade das pessoas com deficiência. Os conflitos do namoro, a capacidade de manter um relacionamento amoroso e a possibilidade de viver uma vida a dois desvinculam a deficiência do discurso hegemônico que a associa a dor e ao sofrimento, como vemos nos excertos a seguir:

O primeiro eleito de Gabriela foi Eric, um colega Down da Apae. O namoro correu bem durante anos. Até que Fábio, um amigo de infância que voltou a frequentar a instituição embaralhou a cabeça dela. Gabriela o paquerou. Ele resistiu. Gabriela insistiu. Fábio cedeu. Durante dois meses, Gabriela levou os dois namorados em banho-maria. $\mathrm{O}$ triângulo amoroso terminou quando Laurinda exigiu que a filha tomasse uma decisão. A opção dela por Fábio fez Eric virar uma fera. Os dois rapazes chegaram a se pegar numa festa de aniversário. (...) Em pouco tempo Fábio e Gabriela estariam morando juntos. (Revista Época online, 2008). 
As declarações também contribuem, a nosso ver, para desmistificar e desconstruir a ideia de que as pessoas com deficiência são dotadas de uma pureza quase angelical. De certa forma, os depoimentos rompem com os essencialismos, evidenciando a possibilidade dessas pessoas poderem ter uma vida afetiva e sexual ativa.

Por outro lado, os discursos produzidos pelas pessoas com deficiência, em relato biográfico, revelam a desinformação acerca de questôes como gravidez, métodos contraceptivos e outros assuntos referentes à capacidade reprodutiva. Tais discursos fazem-nos inferir que embora a gravidez de pessoas com deficiência seja uma possibilidade, é também um tabu para a sociedade e para os próprios pais, principalmente quando se trata da deficiência intelectual. O trecho abaixo é representativo da falta de informação sobre sexualidade a que estão submetidos os sujeitos com deficiência:

Maria Gabriela Andrade Demate, a dona da barriga, também de 28 anos, não fazia ideia de que estava grávida. Embora estivessem juntos havia três anos, dividindo o mesmo teto e a mesma cama, Fábio e Gabriela acreditavam que o sexo entre eles fosse proibido. Seus pais nunca tinham dito, de maneira explícita, que permitiam esse tipo de intimidade. (Revista Época online, 2008).

A crença de que a pessoa com deficiência não possui sexualidade ou não possui desejo sexual faz com que esses sujeitos sejam vistos como eternas crianças. "Ao considerar a pessoa com deficiência como alguém não dotado de sexualidade, negligenciam-se os cuidados contra situações de abuso e se omitem a essas pessoas o direito de acesso à orientação/educação sexual" (MAIA e RIBEIRO, 2010, p.3).

Em contrapartida, apesar do fragmento apresentado anteriormente revelar a desinformação da pessoa com deficiência em relação às consequências do ato sexual, ele explícita também que a suposta inocência atribuída a esses sujeitos talvez possa ser deslocada para o contexto familiar, visto que a ingenuidade parece ser uma característica dos familiares da pessoa com deficiência. Nessa direção, o discurso da mãe revela a crença na incapacidade da filha para o sexo e para a reprodução, como verificamos a seguir:

Mesmo vendo as duas listrinhas do exame, náo acreditava que a minha filha estivesse grávida, afirma Laurinda Ferreira de Andrade. [...] Percebi que estava ficando mais gordinha, mas achei que fosse por comer demais. A gestação avançada, descoberta aos seis meses, gerou pânico e encheu a família de dúvidas. (Revista Época online, 2008).

Dessa forma, o discurso materno posiciona a pessoa com deficiência como um sujeito desprovido de sexualidade, reforçando um estereótipo, ou o mito, de que essas pessoas são assexuadas. Em relação a esse estereótipo, Pinel (1999, p.310) salienta que:

[...] Um dos mitos mais comuns é pensar que as pessoas deficientes são assexuadas. Esta ideia geralmente surge a partir de uma combinação entre a limitada definição de sexualidade e a noção de que o deficiente é neutro, não tem as mesmas necessidades, desejos e capacidades do não-deficiente. 
Nos enunciados é possível perceber que os indivíduos com deficiência também são governados em sua sexualidade, tendo em vista que a decisão sobre a possibilidade de exercê-la é outorgada aos pais, aos familiares, aos médicos ou até mesmo à própria "justiça”. Ao serem vistas como pessoas frágeis e incompletas, os indivíduos com deficiência terão "para o seu bem" a tutela dos mais experientes, que decidirão sua vida sexual e amorosa, como podemos ver nos fragmentos abaixo.

As famílias de Fábio e Gabriela acharam prudente não separar o casal.

Para a lei, os direitos reprodutivos dos deficientes intelectuais são os mesmos de qualquer cidadão. A justiça, no entanto, costuma presumir que nas relaçóes sexuais de não-deficientes com deficientes está embutido algum tipo de abuso. Mesmo quando o sexo é "consentido", a interpretaçáo frequente é que a permissão pode ter sido dada por ingenuidade. (Revista Época online, 2008).

Nesse contexto, os profissionais citados anteriormente, bem como a sociedade, se valem de seus saberes para justificar o motivo pelo qual as pessoas com deficiência intelectual não deveriam e não poderiam exercer o direito da maternidade. Desse modo, parece haver sempre uma relaçáo desigual, marcada pelo poder colonial dos ditos "normais" sobre aqueles que têm alguma deficiência. Nesse sentido, concordamos com Bhabha (1998, p.111) quando afirma que o discurso colonial exerce uma forma de "governamentalidade que, ao delimitar uma nação sujeita, apropria, dirige e domina suas várias esferas de atividade".

Acreditamos que esse direcionamento da sexualidade se deve, sobretudo, ao fato das mulheres com deficiência intelectual não se encaixarem numa representação de mulher-mãe ideal devido às limitaçóes impostas pelo déficit intelectual. A mulher com Síndrome de Down ou com deficiência intelectual não corresponderia aos padrôes preconizados pela sociedade atual como um corpo ideal de mulher capaz de gerar filhos e cuidar dos mesmos. Afinal, na sociedade atual, "ser feminina é ser, também, saudável e bela, para cumprir os desígnios de seu sexo: casamento e procriaçáo" (GOELLNER, 2000, p.85).

As consideraçôes anteriores evidenciam que nessa intrincada rede discursiva, ao mesmo tempo em que circulam representaçóes da deficiência, a partir de padrôes estigmatizados, veiculam-se também outras representaçóes que acabam por subverter os estereótipos a respeito da sexualidade das pessoas com deficiência, desestabilizando alguns mitos e crenças equivocadas a respeito desse assunto. Desse modo, poderíamos dizer, em consonância com Campos (2006, p.95),

[...] que as pessoas com deficiência não são [...] nem anjos, nem demônios, nem assexuadas, nem hipersexualizadas, mas pessoas com alguma ou outra diferença - tal como todos nós - que têm desejos, dúvidas, medos, emoções e que querem também viver os seus corpos e sexualidades.

Mas, nesse discurso multifacetado, o texto cultural põe em ação maneiras específicas de significar, posicionar e nomear os sujeitos com deficiência a partir de uma perspectiva organicista, articulando-se com todo um aparato conceitual advindo de 
um saber médico, constituindo a ideia de deficiência intimamente relacionada ao aspecto biológico, promovendo-se a objetivaçâo desses sujeitos.

\section{discurso médico e a objetivação da deficiência}

$\mathrm{O}$ processo de objetivação do sujeito com deficiência acontece por meio da utilização recorrente de explicações de caráter biológico para descrever e analisar os fenômenos relacionados à deficiência. Assumindo um teor aparentemente informativo, o discurso médico informa acerca das causas, do desenvolvimento e do tratamento das pessoas que apresentam a Síndrome de Down, como podemos ver abaixo:

Entenda a Síndrome de Down

Causa: não existe uma causa. O risco está relacionado à idade materna e é maior nos extremos da vida reprodutiva. Mulheres de 19 a 24 anos dão à luz um bebê Down a cada 1.752 nascidos vivos. Aos 46 anos, a probabilidade é de um Down a cada 33.

O que é: um acidente genético durante a divisão celular do embriáo. O Down tem um cromossomo extra. Pelo menos metade dos Downs náo chega a nascer, pois a mãe sofre aborto espontâneo.

Desenvolvimento: Down não é uma doença e não tem cura. Quase metade dos bebês Downs tem cardiopatia congênita. (Revista Época online, 2008).

Ao analisar os enunciados do quadro "entenda a síndrome de Down", percebemos que, para se falar ou para se compreender a deficiência, é preciso primeiramente apresentar, de forma sumária, um exame de suas causas. Ao elucidar as causas da deficiência, pode-se construir uma visão estanque e fragmentada desta, fazendo com que a diferença seja percebida apenas como algo inato, produto da natureza e não como uma construção social. Uma boa alusão sobre isso pode ser encontrada na afirmação de Tomazini (1998, p.115):

[...] A localização do mal no individuo, como fenômeno de causas endógenas, não mobiliza os mecanismos socioculturais na identificação da diferença. Se mudássemos o eixo de visibilidade, a questão seria remetida ao contexto social, à verificação das condições que conferem a determinados comportamentos a significação de desvio, e reconhece nos atos "doentes", "marginais", "desadaptados" a marca sociocultural.

Outra questão que merece atenção é a conceituação da deficiência, evidenciada no quadro "Entenda a Síndrome de Down". Acreditamos que essa conceituação promove a fixação das diferenças individuais dos sujeitos, dando a impressão de que eles são uma massa amorfa, destituídos de identidade e de individualidade. Sendo assim, a pessoa com deficiência deixa de ser um indivíduo e se transforma num "caso" que, ao mesmo tempo, constitui um objeto para o conhecimento e uma tomada para o poder. Em relação ao "caso", Foucault (2009, p.183) salienta que:

[...] O caso não é mais, como na casuística ou na jurisprudência, um conjunto de circunstâncias que qualificam um ato e podem 
modificar a aplicaçáo de uma regra, é o indivíduo tal como pode ser descrito, mensurado, medido, comparado a outros e isso em sua própria individualidade; e é também o indivíduo que tem que ser treinado ou retreinado, tem que ser classificado, normalizado, excluído, etc.

Diríamos, assim, que o propósito educativo do quadro "Entenda a Síndrome de Down" centra-se justamente na exposição de todos os detalhes patológicos do sujeito, definindo a "doença", apresentando o diagnóstico, pormenorizando as dificuldades, instituindo padrôes de desenvolvimento. É interessante observar que, nesse saber médico, "o corpo humano entra numa maquinaria de poder que o esquadrinha, o desarticula e o recompóe" (FOUCAULT, 2009, p.133). O corpo aqui é objeto de um discurso que, ao enunciar a doença, diz quem é esse sujeito, quais as suas características e como pode reagir em sua condição de doente.

Isso implica, por certo, em reconhecer que o discurso médico, historicamente hegemônico na autoridade de um dizer sobre a deficiência, reaparece no discurso da revista Época, manifestando uma vontade de verdade, estreitamente associada às estruturas de poder e dominação, marcadoras da própria história da pessoa com deficiência. Por outro lado, contrapondo-se ao discurso que fixa a deficiência a partir de um referencial médico, constatamos a existência da construção e disseminação de uma representação da deficiência atrelada à ideia de heroísmo e superação.

\section{A espetacularização da deficiência e a produção do herói}

Encontramos, no artefato cultural analisado, um enaltecimento das capacidades dos sujeitos com deficiência, estabelecendo-se a construção de um personagem heroico que, apesar de todo sofrimento, consegue superar as adversidades, como podemos ver no excerto abaixo:

[...] Gabriela resistiu aos golpes - e revidou -, a ponto de pendurar uma medalha no peito. Dançou balé. Foi rainha de bateria de escola de samba e tocou tamborim numa ala dominada por homens. Gabriela fica indignada por não dirigir. "Se todo mundo pode, por que eu não posso?”, diz. Em Socorro, cidade do interior paulista onde vive, ela é mais popular que o prefeito. Todo mundo conhece um pouco de sua história. (Revista Época online, 2008).

Nesse momento, é importante fazer referência ao trabalho de Goffman (2004), em que opera com o conceito de estigma. $\mathrm{O}$ autor destaca que o estigmatizado é apresentado como se estivesse em exibição, de modo que suas condutas são inalcançáveis pelas outras pessoas, sobretudo porque os outros náo passaram por todas as suas provaçôes, já que não possuem nenhum tipo de deficiência. Assim, "seus menores atos, ele sente, podem ser avaliados como sinais de capacidades notáveis e extraordinárias nessas circunstâncias" (GOFFMAN, 2004, p.16).

A espetacularizaçáo da deficiência, ao revelar as potencialidades desses sujeitos através da exibição dos seus atos heroicos, tem por objetivo a normalização da deficiência, ou seja, fazer da pessoa com deficiência um indivíduo igual aos outros, transformando o corpo anormal em um corpo ordinário, comum, corriqueiro. 
Entendemos que esse tipo de discurso é em si problemático, pois, ao negar a deficiência, mascarando-a através do excesso de atributos afirmativos, corremos o risco de transformar esses sujeitos em figuras grotescas, excêntricas ou caricatas. Como nos diz Bhabha (1998, p.117), "a recusa da diferença transforma o sujeito colonial em um desajustado - uma mímica grotesca ou uma 'duplicação' que ameaça dividir a alma e a pele não diferenciada, completa, do ego”.

Apesar de parecer bem-intencionada, a abordagem da diferença, por meio de atributos heroicos, pode ser danosa para as pessoas com deficiência. Pois, apagar as diferenças, por meio de uma série de atributos afirmativos, a fim de inserir os sujeitos com deficiência na sociedade inclusiva, pode levar as pessoas a acreditarem que a superação da diferença depende apenas de um esforço próprio dos sujeitos com deficiência e de sua capacidade para vencer as adversidades que lhes são impostas pelos sistemas sociais.

\section{Considerações finais}

As narrativas da revista Época vão tecendo em sua materialidade diferentes maneiras de "dizer" a deficiência, fazendo aparecer discursos por vezes antagônicos, enunciados nem sempre lineares, mas que, em seu conjunto e em sua dispersão, produzem diferentes maneiras de captar a verdade sobre os sujeitos com deficiência.

Nesse âmbito, observamos que os discursos da revista se articulam com um aparato conceitual advindo de um saber médico, constituindo a ideia de deficiência intimamente relacionada ao paradigma biológico. Nesse jogo de forças, apresentamse as causas, o diagnóstico e os possíveis tratamentos oferecidos a esses sujeitos.

Nessa forma de significar a deficiência, promove-se uma leitura da deficiência independente do tempo, do lugar e das relaçôes sociais, operando-se uma ritualização que apaga as diferenças, esterilizando, dessa maneira, a possibilidade de invençấo de novas configuraçóes sobre os sujeitos com deficiência.

Se, por um lado, os discursos veiculados na reportagem produzem a ideia de uma sexualidade atrelada aos aspectos biológicos, evidenciados através de um discurso médico, por outro, produzem também a representação cultural de que as pessoas com deficiência podem usufruir de sua sexualidade, de uma vida a dois e da experiência da maternidade.

Nesse âmbito, é importante promover um espaço narrativo para que as pessoas com deficiência possam contar suas próprias histórias, assegurando-lhes o direito de falar e de produzir contrarrepresentaçôes que compliquem ou desestabilizem as certezas, que destruam os estereótipos, mostrando que existem diferentes formas de ser "deficiente" e de exercer a sexualidade. Em consonância com Costa (2005, p.50), acreditamos que devemos reivindicar o direito dos grupos e dos indivíduos excluídos de descreverem a si próprios, de falar do lugar que ocupam e, sobretudo, de "inventarem as narrativas que os definem como participantes da história”.

Num momento em que se fala tanto de inclusão, em que se salienta esse paradigma como forma de transposição de barreiras sociais e segregadoras, é preciso 
cautela com os discursos que continuam tendo o poder de narrar a deficiência, mantendo um olhar vigilante em relação aos saberes e poderes dos novos atores sociais que entram em cena na produção dos sujeitos com deficiência.

Embora reconheçamos as dificuldade ou impossibilidades de identificar todos os sentidos sobre a deficiência que circulam no texto cultural analisado, esperamos que as discussões e análises apresentadas possam, de alguma maneira, convidar-nos a olhar com providência as formas de narrar a deficiência nos discursos midiáticos, atentando para as histórias que são contadas, para as maneiras como os sujeitos são posicionados e, principalmente, para as relaçôes de poder-saber produtoras de significados sobre as pessoas com deficiência.

\section{Referências}

ALBUQUERQUE JUNIOR, D. M. A invençáo do nordeste e outras artes. São Paulo: Cortez, 2011.

BHABHA, H. K. O local da cultura. Belo Horizonte: Ed. UFMG, 1998.

CAMPOS, M. P. Nem anjos, nem demônios: discursos e representaçóes de corpo e sexualidade de pessoas com deficiências na Internet. 2006. Dissertação (Mestrado em Educação) - Programa de Pós-Graduação em Educação da Universidade Luterana do Brasil, Canoas, 2006.

COSTA, M. V. Currículo e política cultural. In: COSTA, Marisa Vorraber (Org.). O currículo nos limiares do contemporâneo. 4. ed. Rio de Janeiro: DP \& A, 2005. p. 37-67.

ÉPOCA ONLINE, REVISTA. 2008. Mamãe é down. Disponível em: <http://revistaepoca.globo.com/Revista/Epoca/0,,EMI11982-15228,00-MAMAE+E+DOWN.html>. Acesso em: 18 mai. 2016.

FOUCAULT, M. O sujeito e o Poder. In: DREYFUS, H.; RABINOW, Paul. M. Foucault, uma trajetória filosófica: para além do estruturalismo e da hermenêutica. Rio de Janeiro: Forense Universitária, 1995. p. 231-249.

FOUCAUlT, M. Ordem do discurso. Traduçâo de Laura Fraga de Almeida Sampaio. 16. ed. São Paulo: Ediçôes Loyola, 1996.

FOUCAULT, M. Vigiar e punir: nascimento da prisão. Tradução de Raquel Ramalhete. 37. ed. Petrópolis, RJ: Vozes, 2009

FOUCAULT, M. Arqueologia do saber. Tradução de Luiz Felipe Baeta Neves. 7. ed. Rio de Janeiro: Forense Universitária, 2013.

GOELLNER, S.V. A produção cultural do corpo. In: LOURO, G. Gênero, sexualidade e educação: uma perspectiva pós-estruturalista. Petrópolis, RJ: Vozes, 2000. p. 28-29.

GOFFMAN, E. Estigma: notas sobre a manipulaçấo da identidade deteriorada. 4. ed. Rio de Janeiro: editora Guanabara, 2004.

HALL, S. The work of representation. In: Hall, S. (Org). Representation Cultural Representations and Signifying Practices. London: Sage/Open University, 1997. p.15-71.

LARROSA, J. Tecnologias do eu e educação. In: SILVA, Tomaz Tadeu. O sujeito da educaçáo. Petrópolis: Vozes, 1994, p.35-86. p.35-86.

MAIA, A. C. B; RIBEIRO, P. R. M. Desfazendo mitos para minimizar o preconceito sobre a sexualidade de pessoas com deficiências. Revista Brasileira de Educaçáo Especial, Marília, v.16, n.2. maio/ago. 2010.

PINEL, A. A restauração da Vênus de Milo: dos mitos à realidade sexual da pessoa deficiente. In: RIBEIRO, Marcos. (Org.). Educaçáo sexual: novas ideias, novas conquistas. Rio de Janeiro: Rosa dos Tempos, 1999. p.307-325.

STEINBERG, S. Kindercultura: a construção da infância pelas grandes corporaçốes. In: SILVA, L. H.; AZEVEDO, J. C.; SANTOS, E. (Org.). Identidade social e a construção do conhecimento. Porto Alegre: Secretaria Municipal da Educaçáo de Porto Alegre, 1997. p. 98-145.

TOMAZINI, M. E. A. Expatriação social e segregação institucional da diferença: reflexôes. In: Bianchetti, Lucídio; Freire, Ida Mara (Orgs.). Um olhar sobre a diferença: interação, trabalho e cidadania. Campinas, SP: Papirus, 1998. p.111-133. 
WOODWARD, K. Identidade e diferença: uma introduçấo teórica e conceitual. In: SILVA, Tomaz T. da. (Org.). Identidade e diferença. Petrópolis: Vozes, 2009. p. 7-72.

\section{Correspondência}

Ana Flávia Teodoro de Mendonça Oliveira - Universidade Federal de Goiás, Faculdade de Educação. Rua 235 (Delenda Rezende de Melo) s/n Setor Universitário CEP: 74605-050 - Goiânia, Goiás, Brasil.

E-mail: anaflavia_teodoro@hotmail.com - clarissa.araujo@yahoo.com.br

Recebido em 29 de novembro de 2016

Aprovado em 16 de março de 2017 
